\title{
Alterações neurológicas associadas a infecções por arbovírus no Brasil
}

\author{
Neurological disorders associated with arbovirus infections in Brazil
}

Trastornos neurológicos asociados con infecciones por arbovirus en Brasil

\begin{abstract}
Pedro Jackson dos Santos Benicio ${ }^{1 *}$, Maria Clara Sousa Lima1', Lady Jane da Silva Macedo', José Lopes Pereira Júnior ${ }^{1}$, Tereza Cristina de Carvalho Souza Garcês ${ }^{1}$.
\end{abstract}

\section{RESUMO}

Objetivo: Analisar as principais alterações neurológicas associadas à infecção por arbovírus no Brasil. Métodos: Tratase de uma revisão sistemática da literatura realizada nas bases de dados Scientific Electronic Library Online (SciELO), Medical Literature Analysis and Retrieved System (MEDLINE), Literatura Latino-americana e do Caribe em Ciências da Saúde (LILACS), U.S. National Library of Medicine (PubMed) e Biblioteca Virtual de Saúde (BVS), por meio da inclusão de artigos originais, estudos de coorte, observacional, séries e relatos de casos realizados no Brasil e publicados em periódicos nacionais e internacionais no período de 2010 a 2020. Resultados: Inicialmente foram identificados 1445 artigos científicos. Após a leitura dos títulos e resumos, 98 estudos foram avaliados. Em seguida, 25 artigos foram selecionados para a presente revisão de literatura. O estudo identificou alterações associadas à infecção por ZIKV, CHIKV, DENV e WNV. As alterações descritas foram Síndrome congênita associada à infecção por ZIKV, síndrome de Guillain-Barré, encefalite, meningoencefalite, polineuropatia, neuropatia, Mielite Transversa Aguda, corroborando com achados semelhantes na literatura. Considerações finais: O estudo permitiu identificar as principais complicações neurológicas associadas às infecções por arbovírus no Brasil, destacando-se a meningite, encefalite, neuropatia sensorial, mielite transversa aguda e a síndrome congênita associada à infecção por ZIKV.

Palavras-chave: Infecções por arbovirus, Manifestações neurológicas, Doenças do sistema nervoso, Complicações.

\section{ABSTRACT}

Objective: To analyze the main neurological changes associated with arbovirus infection in Brazil. Methods: This is a systematic review of the literature carried out in the databases Scientific Electronic Library Online (SciELO), Medical Literature Analysis and Retrieved System (MEDLINE), Latin American and Caribbean Literature in Health Sciences (LILACS), US National Library of Medicine (PubMed) and Biblioteca Virtual de Saúde (BVS), through the inclusion of original articles, cohort studies, observational, case series and case reports conducted in Brazil and published in national and international journals in the period 2010 to 2020. Results: Initially, 1445 scientific articles were identified. After reading the titles and abstracts, 98 studies were evaluated. Then, 25 articles were selected for the present literature review. The study identified changes associated with infection by ZIKV, CHIKV, DENV and WNV. The changes described were Congenital Syndrome associated with ZIKV infection, Guillain-Barré syndrome, encephalitis, meningoencephalitis, polyneuropathy, neuropathy, Acute Transverse Myelitis, corroborating similar findings in the literature. Final considerations: The study made it possible to identify the main neurological complications associated with arbovirus infections in Brazil, especially meningitis, encephalitis, sensory neuropathy, acute transverse myelitis and the congenital syndrome associated with ZIKV infection.

Keywords: Arbovirus infections, Neurologic manifestations, Nervous system diseases, Complications.

\section{RESUMEN}

Objetivo: Analizar los principales cambios neurológicos asociados a la infección por arbovirus en Brasil. Métodos: Se trata de una revisión sistemática de la literatura realizada en las bases de datos Scientific Electronic Library Online (SciELO), Medical Literature Analysis and Retrived System (MEDLINE), Latin American and Caribbean Literature in Health Sciences (LILACS), EE. UU. Biblioteca Nacional de Medicina (PubMed) y Biblioteca Virtual en Salud (BVS), mediante la inclusión de artículos originales, estudios de cohortes, observacionales, series de casos e informes de casos realizados en Brasil y publicados en revistas nacionales e internacionales en el período. 2010 a 2020. Resultados: Inicialmente se identificaron 1445 artículos científicos. Después de leer los títulos y resúmenes, se evaluaron 98 estudios. Luego, se seleccionaron 25 artículos para la presente revisión de la literatura. El estudio identificó cambios asociados con la infección por ZIKV, CHIKV, DENV y WNV. Los cambios descritos fueron Síndrome congénito asociado a infección por ZIKV, síndrome de Guillain-Barré, encefalitis, meningoencefalitis, polineuropatía, neuropatía, mielitis transversa aguda, corroborando hallazgos similares en la literatura. Consideraciones finales: El estudio permitió identificar las principales complicaciones neurológicas asociadas a las infecciones por arbovirus en Brasil, especialmente meningitis, encefalitis, neuropatía sensorial, mielitis transversa aguda y el síndrome congénito asociado a la infección por ZIKV.

Palabras clave: Infecciones por arbovirus, Manifestaciones neurológicas, Enfermedades del sistema nervioso, Complicaciones.

${ }^{1}$ Faculdade de Ciências Humanas, Exatas e da Saúde do Piauí/ Instituto de Educação Superior do Vale do Parnaíba (FAHESP/IESVAP), Parnaíba - PI. *E-mail: pedrojacksonbenicio@gmail.com 


\section{INTRODUÇÃO}

Os arbovírus representam um importante problema de saúde pública em todo o mundo, necessitando de medidas de prevenção e controle mais eficazes (DONALISIO MR, et al., 2017). São vírus transmitidos por artrópodes e que possuem parte do seu ciclo replicativo ocorrendo nos próprios insetos, apresentam hospedeiros variados, sendo capazes de manifestar doenças em humanos e em outros animais (LOPES N, et al., 2014). Aqueles de importância para a saúde humana pertencem às famílias Alphavirus, Togaviridae, Flaviviridae, Bunyaviridae, Reoviridae e Rhabdoviridae, destacando-se o vírus da Dengue (DENV), Vírus Chikungunya (CHIKV), Zika vírus (ZIKV), Vírus da febre amarela (YFV) e outros (DONALISIO MR, et al., 2017; LOPES N, et al., 2014).

As arboviroses são transmitidas em áreas urbanas ou periurbanas por mosquitos do gênero Aedes, presentes em todos os continentes. O mosquito apresenta acentuada antropofilia (preferência por sangue humano), sendo bastante reconhecida sua atividade no ambiente intradomiciliar que favorece o ciclo de transmissão. No Brasil, o clima predominantemente tropical e as extensas áreas de florestas contribuem para a existência do vetor, além da ocorrência de desmatamentos, o deslocamento populacional e a falta de planejamento na ocupação de regiões urbanas, tonando-se um local endêmico para a ocorrência dessas doenças (LOPES N, et al., 2014). Segundo o Ministério da Saúde, até junho de 2020 foram notificados 823.738 casos prováveis de dengue no país, 40.352 casos de febre Chikungunya e 3.692 casos de febre do Zika (BRASIL, 2020). Para o mesmo período, o país registrou 374 óbitos por dengue e 9 por febre Chikungunya (BRASIL, 2020).

As arboviroses apresentam sinais e sintomas semelhantes, podendo variar de quadros assintomáticos a formas graves, sendo que os mais frequentes são: febre, mialgia/artralgia e exantema (LOPES N, et al., 2014). Além disso, as infecções por arbovírus estão potencialmente relacionadas a importantes manifestações neurológicas, como a síndrome de Guillain-Barré, encefalite, mielite, mononeuropatias, polineuropatias e meningite asséptica. Dessa forma, saber reconhecer as manifestações clínicas características dos pacientes com arbovirose é fundamental para o diagnóstico precoce das formas graves, bem como para a instituição da terapêutica adequada, diminuindo assim a morbimortalidade (PEREIRA AGL et al., 2018).

O diagnóstico das arboviroses representa um desafio para a saúde pública, na medida em que essas doenças apresentam quadro clínico semelhante, sendo ainda mais dificultado pela possibilidade de ocorrência de infecção cruzada em testes sorológicos, haja vista a ampla variedade de arbovírus circulantes no país (LIMA-CAMARA TN, 2016). Assim, o diagnóstico laboratorial pode ser realizado por métodos diretos para detecção viral, como o isolamento do vírus por inoculação em células ou identificação do vírus por transcrição reversa seguida de reação em cadeia de polimerase (RT-PCR). A confirmação do agente viral pode ser feita, também, por meio da pesquisa de anticorpos por testes sorológicos, ensaios de neutralização, fixação de complemento, inibição da hemaglutinação e imuno-histoquímica.

A apresentação endêmica das arboviroses no Brasil, os desafios para um diagnóstico acertado dessas infecções virais e a similaridade do quadro clínico, além de outros fatores associados, torna esse grupo de doenças um problema importante de saúde pública. Ademais, a ocorrência de complicações neurológicas representa mais um desafio na abordagem ao paciente com arbovirose, exigindo amplo conhecimento acerca dessas doenças pelos profissionais de saúde para orientar o manejo e terapêutica adequada.

Dessa forma, o presente estudo tem como objetivo analisar através de uma revisão sistemática da literatura as principais alterações neurológicas associadas à infecção por arbovírus no Brasil.

\section{MÉTODOS}

Trata-se de uma revisão sistemática da literatura realizada nas seguintes bases de dados eletrônicas: Scientific Electronic Library Online (SciELO); Medical Literature Analysis and Retrieved System (MEDLINE); Literatura Latino-americana e do Caribe em Ciências da Saúde (LILACS); U.S. National Library of Medicine (PubMed); Biblioteca Virtual de Saúde (BVS). 
As buscas foram conduzidas de acordo com os seguintes descritores presentes no Descritor em Ciências da Saúde (DeCS), utilizando o operador booleano "AND", em português: "infecções por arbovírus", "manifestações neurológicas", "doenças do Sistema Nervoso", "complicações". E em inglês: "Arbovirus infections", "Neurologic Manifestations", "Nervous System diseases", "complications".

Dessa forma, foram incluídos artigos originais, estudos de coorte, observacional, série de casos e relatos de casos realizados no Brasil que abordaram o tema alterações neurológicas e arbovírus, publicados em periódicos nacionais e internacionais no período de 2010 a 2020, que estavam disponíveis para livre acesso, em língua portuguesa e inglesa, indexados em uma das bases de dados citadas anteriormente. Os artigos que não estavam de acordo com os critérios definidos, aqueles que fugiam da temática central ou estudos experimentais realizados em animais, foram excluídos.

Inicialmente, foi realizada a leitura dos títulos dos artigos. Em seguida, a análise dos resumos orientou a seleção, na qual os estudos foram incluídos com base nos critérios de inclusão e exclusão previamente definidos. Portanto, os estudos que correspondiam aos objetivos propostos foram selecionados para a presente revisão de literatura (Figura 1).

Para a seleção dos artigos construiu-se um formulário com as seguintes informações: autor e ano, título do estudo, metodologia, local em que foi realizado, população do estudo, vírus identificado, método diagnóstico e alterações neurológicas.

Figura 1 - Método de seleção dos artigos.

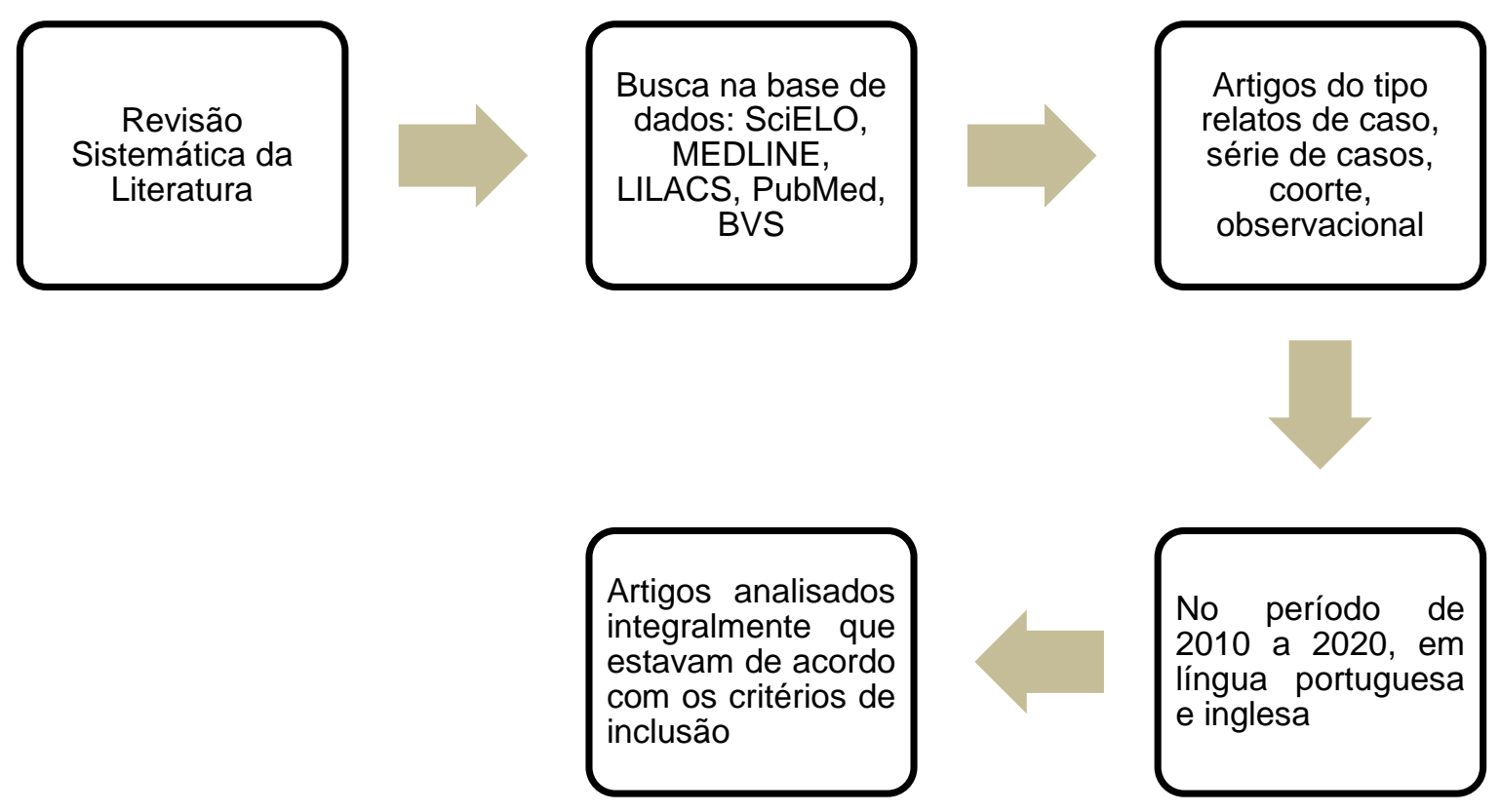

Fonte: Benicio PJS, et al., 2020.

\section{RESULTADOS}

De acordo com as combinações realizadas, inicialmente foram identificados 1445 artigos científicos $($ SciELO= 21; MEDLINE= 79; LILACS= 20; PUBMED= 1018; BVS= 307). Após a leitura dos títulos e resumos, 98 estudos foram avaliados.

Em seguida, 25 estudos que respondiam ao objetivo proposto foram selecionados para a presente revisão de literatura, considerando os critérios de inclusão e exclusão descritos. Os estudos em espanhol ou francês, duplicações, de acesso restrito, aqueles envolvendo animais ou que não atendiam aos objetivos, foram excluídos (Figura 2). 
Figura 2 - Artigos selecionados a partir dos critérios estabelecidos e disponíveis nas bases de dados.

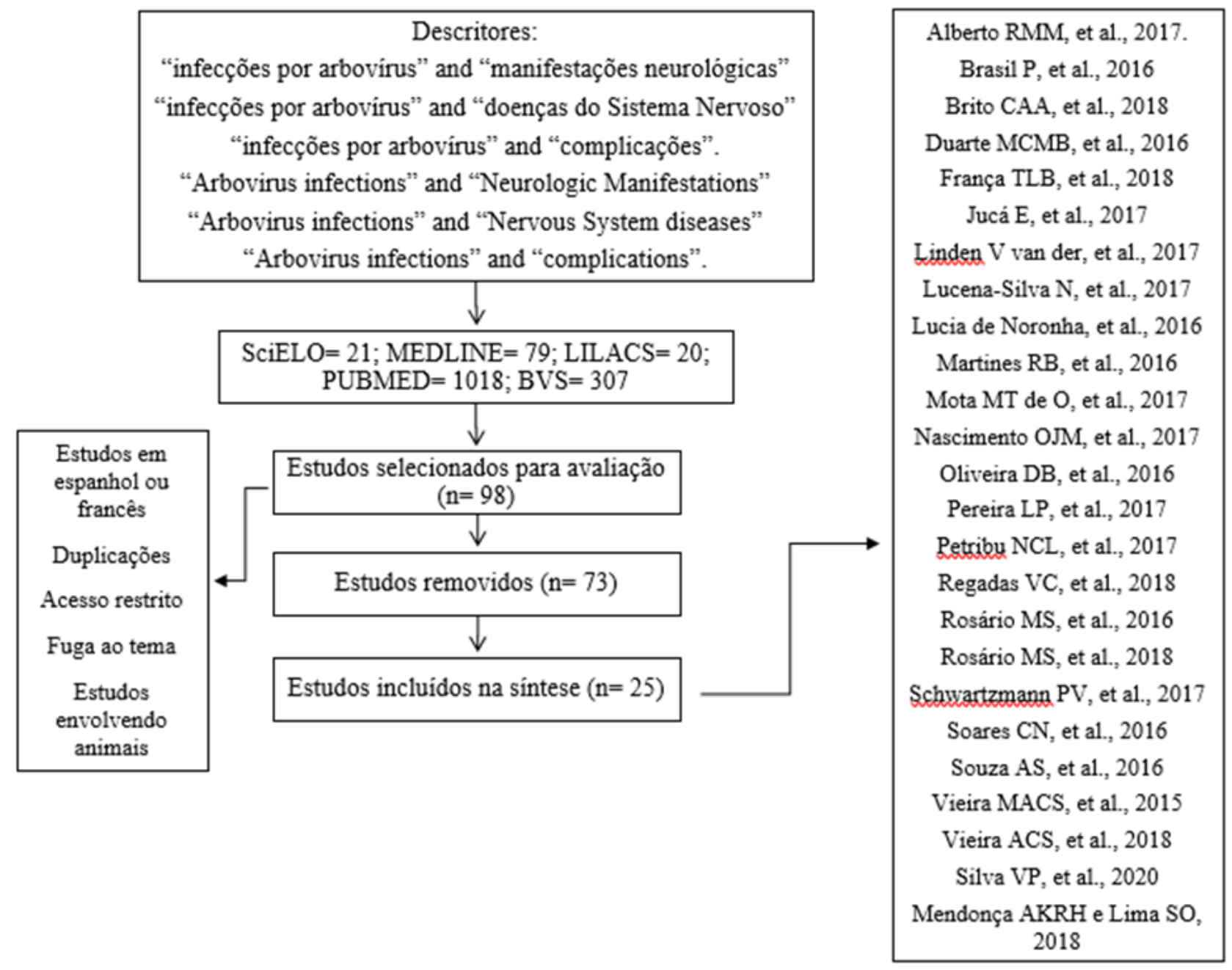

Fonte: Benicio PJS, et al., 2020.

Desses, 36\% dos estudos foram publicados em 2017, correspondendo à maioria dos trabalhos selecionados, seguidos por aqueles publicados em 2016, somando $32 \%$. Em 2018, os artigos selecionados corresponderam a 24\%, e apenas um estudo selecionado nos anos de 2015 e 2020, sendo 4\%.

Em relação ao tipo de estudo, verificou-se que $72 \%$ corresponderam a relatos de caso, $20 \%$ eram série de casos e houve um estudo observacional transversal e outro do tipo coorte, cada um representando $4 \%$ dos artigos selecionados.

A região Nordeste concentrou o maior quantitativo de casos descritos, cerca de $61 \%$ dos estudos. Em seguida, a região Sudeste apresentou cerca de $19 \%$ dos trabalhos selecionados e, ainda, um artigo descrevendo um caso na região Sul. Em cerca de $15 \%$ dos estudos, a região não foi definida, sabendo-se apenas que eram relatados casos do Brasil.

Os estudos relataram, em sua maioria, infecções por ZIKV, representando $64 \%$ dos artigos selecionados. Identificaram-se relatos de infecção por CHIKV (16\%) e por DENV (8\%). Houve, ainda, um estudo relatando um caso de infecção por WNV, uma co-infecção DENV-CHIKV e uma infecção por ZIKV com reativação do Varicella zoster vírus.

Acerca das alterações neurológicas identificadas, 32\% dos estudos relataram casos de Síndrome Congênita Associada à Infecção por ZIKV, 16\% descreveram casos de encefalite por arbovírus e 8\% dos estudos selecionados apresentaram polineuropatia e Síndrome de Guillain-Barré como complicações dessas infecções virais. Os artigos incluídos relatavam, ainda, casos de meningite, meningoencefalite, neuropatia, mielite transversa aguda, além de outras complicações. 
Quadro 1 - Síntese dos resultados.

\begin{tabular}{|c|c|c|c|c|c|c|c|}
\hline Autor e ano & Título & Metodologia & Local & $\begin{array}{c}\text { População do } \\
\text { estudo }\end{array}$ & $\begin{array}{c}\text { Vírus } \\
\text { identificado }\end{array}$ & Método diagnóstico & Alterações neurológicas \\
\hline $\begin{array}{l}\text { Duarte MCMB, et } \\
\text { al., } 2016\end{array}$ & $\begin{array}{l}\text { Infecção por Chikungunya em } \\
\text { lactentes }\end{array}$ & $\begin{array}{l}\text { Estudo de série de } \\
\text { casos com caráter } \\
\text { analítico }\end{array}$ & Recife, PE & 14 lactentes & CHIKV & $\begin{array}{l}\text { Ensaio imunoenzimático } \\
\text { (ELISA) }\end{array}$ & $\begin{array}{l}\text { Três crianças apresentaram } \\
\text { meningite }\end{array}$ \\
\hline $\begin{array}{l}\text { Schwartzmann } \\
\text { PV, et al., } 2017\end{array}$ & $\begin{array}{l}\text { Zika Virus } \\
\text { Meningoencephalitis in an } \\
\text { Immunocompromised Patient }\end{array}$ & Relato de caso & $\begin{array}{l}\text { Ribeirão Preto, } \\
\text { SP }\end{array}$ & Paciente adulto & ZIKV & $\begin{array}{l}\text { Reação em Cadeia de } \\
\text { Polimerase- Transcriptase } \\
\text { Reversa (RT-PCR) }\end{array}$ & $\begin{array}{l}\text { Meningoencefalite viral, } \\
\text { apresentando convulsão } \\
\text { generalizada, hemiplegia } \\
\text { transitória do lado esquerdo e } \\
\text { cefaleia, confusão mental, } \\
\text { alucinações. }\end{array}$ \\
\hline $\begin{array}{l}\text { Nascimento } \\
\text { OJM, et al., } 2017\end{array}$ & $\begin{array}{l}\text { Zika Virus infection- } \\
\text { associated acute } \\
\text { Transient Polyneuritis }\end{array}$ & $\begin{array}{l}\text { Estudo de série de } \\
\text { casos }\end{array}$ & $\begin{array}{l}\text { Rio de Janeiro, } \\
\text { RJ }\end{array}$ & Três pacientes & ZIKV & RT-PCR no sangue e LCR & Polineuropatia transitória aguda \\
\hline $\begin{array}{l}\text { Alberto RMM, et } \\
\text { al., } 2017 .\end{array}$ & $\begin{array}{l}\text { A novel phenotype of Zika } \\
\text { virus-related neurological } \\
\text { disease: sensory } \\
\text { neuronopathy }\end{array}$ & Relato de caso & Salvador, BA. & $\begin{array}{l}\text { Mulher de } 42 \\
\text { anos }\end{array}$ & ZIKV & RT-PCR na urina & $\begin{array}{l}\text { Neuropatia sensorial } \\
\text { aguda/subaguda. }\end{array}$ \\
\hline $\begin{array}{l}\text { Lucia de Noronha } \\
\text { et al., } 2016\end{array}$ & $\begin{array}{l}\text { Zika virus damages the human } \\
\text { placental } \\
\text { barrier and presents marked } \\
\text { fetal neurotropism }\end{array}$ & $\begin{array}{l}\text { Estudo de série de } \\
\text { casos }\end{array}$ & $\begin{array}{l}\text { Região } \\
\text { Nordeste e } \\
\text { Região Sul, } \\
\text { Brasil }\end{array}$ & $\begin{array}{l}\text { Mulher, } 31 \text { anos. } \\
\text { Recém-nascido, } \\
\text { sexo feminino. } \\
\text { Recém-nascido, } \\
\text { sexo masculino. } \\
\text { Recém-nascido, } \\
\text { sexo masculino. } \\
\text { Mulher, } 31 \text { anos. }\end{array}$ & ZIKV & $\begin{array}{l}\text { Imunohistoquímica } \\
\text { RT-PCR } \\
\text { Identificação do anticorpo IgM } \\
\text { pelo método ELISA }\end{array}$ & $\begin{array}{l}\text { Aborto espontâneo. } \\
\text { Microcefalia e óbito fetal. } \\
\text { Malformações nos membros e } \\
\text { genitália. }\end{array}$ \\
\hline $\begin{array}{l}\text { Vieira MACS, et } \\
\text { al., } 2015\end{array}$ & $\begin{array}{l}\text { West Nile Virus Encephalitis: } \\
\text { The First Human Case } \\
\text { Recorded in Brazil }\end{array}$ & Relato de caso & $\begin{array}{l}\text { Aroeiras do } \\
\text { Itaim, Piauí, } \\
\text { Brasil }\end{array}$ & Homem, 52 anos & $\begin{array}{l}\text { West Nile vírus } \\
\text { (WNV) }\end{array}$ & $\begin{array}{l}\text { Sorologia IgM anti-WNV } \\
\text { reagente foi realizada por } \\
\text { ensaio imunoenzimático de } \\
\text { captura (MAC-ELISA) }\end{array}$ & Encefalite e paralisia flácida. \\
\hline $\begin{array}{l}\text { Mota MTO, et al., } \\
2017\end{array}$ & $\begin{array}{l}\text { Transverse Myelitis as an } \\
\text { Unusual Complication of } \\
\text { Dengue Fever }\end{array}$ & Relato de caso & $\begin{array}{l}\text { São José do } \\
\text { Rio Preto, São } \\
\text { Paulo, Brasil }\end{array}$ & Homem, 21 anos & DENV & $\begin{array}{l}\text { Testes rápidos para detecção de } \\
\text { antígeno viral e para detecção } \\
\text { de IgM e IgG }\end{array}$ & Mielite Transversa aguda \\
\hline $\begin{array}{l}\text { Brito CAA, et al., } \\
2018\end{array}$ & $\begin{array}{l}\text { Persistent detection of Zika } \\
\text { virus RNA from } \\
\text { an infant with severe } \\
\text { microcephaly - a case } \\
\text { report }\end{array}$ & Relato de caso & $\begin{array}{l}\text { Recife, } \\
\text { Pernambuco, } \\
\text { Brasil }\end{array}$ & $\begin{array}{l}\text { Recém-nascido, } \\
\text { sexo feminino }\end{array}$ & ZIKV & $\begin{array}{l}\text { RT-PCR com amostras do soro } \\
\text { e LCR. } \\
\text { Teste sorológico de } \\
\text { neutralização por redução de } \\
\text { placas (PRNT } 50 \text { ) realizado com } \\
\text { amostras de LCR }\end{array}$ & $\begin{array}{l}\text { Síndrome Congênita associada à } \\
\text { infecção pelo vírus Zika }\end{array}$ \\
\hline $\begin{array}{l}\text { Martines RB, et } \\
\text { al., } 2016\end{array}$ & $\begin{array}{l}\text { Pathology of congenital Zika } \\
\text { syndrome in Brazil: a case } \\
\text { series }\end{array}$ & Série de casos & $\begin{array}{l}\text { Rio Grande do } \\
\text { Norte, Brasil. } \\
\text { Piauí, Brasil }\end{array}$ & $\begin{array}{l}\text { Três casos fatais } \\
\text { (dois recém- } \\
\text { nascidos e um } \\
\text { bebê de } 2 \\
\text { meses) } \\
\text { e dois abortos } \\
\text { espontâneos }\end{array}$ & ZIKV & RT-PCR & $\begin{array}{l}\text { Microcefalia e artrogripose severa. } \\
\text { Aborto espontâneo e óbito fetal. } \\
\text { Síndrome Congênita associada à } \\
\text { infecção por ZIKV }\end{array}$ \\
\hline
\end{tabular}




\begin{tabular}{|c|c|c|c|c|c|c|c|}
\hline Autor e ano & Título & Metodologia & Local & $\begin{array}{c}\text { População do } \\
\text { estudo }\end{array}$ & $\begin{array}{c}\text { Vírus } \\
\text { identificado }\end{array}$ & Método diagnóstico & Alterações neurológicas \\
\hline $\begin{array}{l}\text { Rosário MS, et } \\
\text { al., } 2018\end{array}$ & $\begin{array}{l}\text { Opsoclonus-myoclonus-ataxia } \\
\text { syndrome associated with } \\
\text { chikungunya and dengue virus } \\
\text { co-infection }\end{array}$ & Relato de caso & $\begin{array}{l}\text { Salvador, } \\
\text { Bahia, Brasil }\end{array}$ & Mulher, 38 anos & $\begin{array}{l}\text { Coinfecção } \\
\text { DENV-CHIKV }\end{array}$ & $\begin{array}{l}\text { Detecção de anticorpos } \\
\text { especificos IgM pelo método } \\
\text { ELISA positivo para DENV. } \\
\text { RT-PCR com amostra do } \\
\text { plasma positivo para DENV e } \\
\text { CHIKV. }\end{array}$ & $\begin{array}{l}\text { Encefalite e Síndrome de } \\
\text { opsoclonia-mioclonia-ataxia }\end{array}$ \\
\hline $\begin{array}{l}\text { Regadas VC, et } \\
\text { al., } 2018\end{array}$ & $\begin{array}{l}\text { Microcephaly caused by } \\
\text { congenital Zika virus infection } \\
\text { and viral } \\
\text { detection in maternal urine } \\
\text { during pregnancy }\end{array}$ & Relato de caso & Brasil & $\begin{array}{l}\text { Mulher, } 25 \text { anos. } \\
\text { O recém-nascido } \\
\text { apresentou } \\
\text { alterações } \\
\text { cranianas e } \\
\text { encefálicas } \\
\end{array}$ & ZIKV & $\begin{array}{l}\text { RT-PCR usando amostra de } \\
\text { urina materna }\end{array}$ & $\begin{array}{l}\text { Microcefalia, vetriculomegalia e } \\
\text { calcificações cerebrais. }\end{array}$ \\
\hline $\begin{array}{l}\text { Oliveira DB, et } \\
\text { al., } 2016\end{array}$ & $\begin{array}{l}\text { Infection of the central nervous } \\
\text { system with dengue virus } 3 \\
\text { genotype I causing } \\
\text { neurological manifestations in } \\
\text { Brazil }\end{array}$ & Relato de caso & $\begin{array}{l}\text { Belo Horizonte, } \\
\text { Minas Gerais }\end{array}$ & Mulher, 21 anos & DENV & RT-PCR & $\begin{array}{l}\text { Convulsão generalizada, confusão } \\
\text { mental e alterações de } \\
\text { comportamento. }\end{array}$ \\
\hline $\begin{array}{l}\text { Jucá E, et al., } \\
2017\end{array}$ & $\begin{array}{l}\text { Hydrocephalus associated to } \\
\text { congenital Zika syndrome: } \\
\text { does } \\
\text { shunting improve clinical } \\
\text { features? }\end{array}$ & Coorte descritivo & $\begin{array}{l}\text { Fortaleza, } \\
\text { Ceará }\end{array}$ & 115 pacientes & ZIKV & Não traz essa informação & $\begin{array}{l}\text { Síndrome Congênita associada à } \\
\text { infecção pelo vírus Zika. }\end{array}$ \\
\hline $\begin{array}{l}\text { Brasil P, et al., } \\
2016\end{array}$ & $\begin{array}{l}\text { Guillain-Barré syndrome } \\
\text { associated with Zika virus } \\
\text { infection }\end{array}$ & Relato de caso & $\begin{array}{l}\text { Rio de Janeiro, } \\
\text { Rio de Janeiro }\end{array}$ & Mulher, 24 anos & ZIKV & $\begin{array}{l}\text { RT-PCR com amostras do soro, } \\
\text { LCR, saliva e urina }\end{array}$ & Síndrome de Guillain-Barré \\
\hline $\begin{array}{l}\text { Rosário MS, et } \\
\text { al., } 2016\end{array}$ & $\begin{array}{l}\text { Case Report: Guillain-Barré } \\
\text { Syndrome after Zika Virus } \\
\text { Infection in Brazil }\end{array}$ & Relato de caso & Salvador, Bahia & $\begin{array}{l}\text { Mulher, } 49 \text { anos. } \\
\text { Homem, } 22 \text { anos. }\end{array}$ & ZIKV & $\begin{array}{l}\text { Detecção de anticorpos } \\
\text { específicos IgM para ZIKV pelo } \\
\text { método ELISA }\end{array}$ & Síndrome de Guillain-Barré. \\
\hline $\begin{array}{l}\text { França TLB, et } \\
\text { al., } 2018\end{array}$ & $\begin{array}{l}\text { Growth and development of } \\
\text { children with } \\
\text { Microcephaly associated with } \\
\text { Congenital } \\
\text { Zika Virus Syndrome in Brazil }\end{array}$ & $\begin{array}{l}\text { Estudo } \\
\text { observacional, } \\
\text { analítico, transversal }\end{array}$ & $\begin{array}{l}\text { Rio Grande do } \\
\text { Norte, Brasil }\end{array}$ & $\begin{array}{l}8 \text { crianças com } \\
\text { Síndrome } \\
\text { Congênita } \\
\text { associada à } \\
\text { infecção pelo } \\
\text { vírus Zika e } 16 \\
\text { crianças sem } \\
\text { alterações } \\
\end{array}$ & ZIKV & $\begin{array}{l}\text { Diagnóstico clínico- } \\
\text { epidemiológico }\end{array}$ & $\begin{array}{l}\text { Síndrome Congênita associada à } \\
\text { infecção pelo vírus Zika. }\end{array}$ \\
\hline $\begin{array}{l}\text { Petribu NCL, et } \\
\text { al., } 2017\end{array}$ & $\begin{array}{l}\text { Follow-up brain imaging of } 37 \\
\text { children with congenital Zika } \\
\text { syndrome: } \\
\text { case series study }\end{array}$ & Série de casos & $\begin{array}{c}\text { Recife, } \\
\text { Pernambuco, } \\
\text { Brasil }\end{array}$ & 37 crianças. & ZIKV & $\begin{array}{l}\text { Diagnóstico confirmado (RT- } \\
\text { PCR, IgM específico para Zika } \\
\text { vírus, Teste sorológico de } \\
\text { neutralização por redução de } \\
\text { placas com amostra do LCR ou } \\
\text { soro) ou provável, como definido } \\
\text { pelo Ministério da Saúde } \\
\text { Brasileiro }\end{array}$ & $\begin{array}{l}\text { Síndrome Congênita associada à } \\
\text { infecção pelo vírus Zika. }\end{array}$ \\
\hline
\end{tabular}




\begin{tabular}{|c|c|c|c|c|c|c|c|}
\hline Autor e ano & Título & Metodologia & Local & $\begin{array}{c}\text { População do } \\
\text { estudo }\end{array}$ & $\begin{array}{c}\text { Vírus } \\
\text { identificado }\end{array}$ & Método diagnóstico & Alterações neurológicas \\
\hline $\begin{array}{l}\text { Souza AS, et al., } \\
2016\end{array}$ & $\begin{array}{l}\text { Fetal Infection by Zika Virus in } \\
\text { the } \\
\text { Third Trimester: Report of } 2 \\
\text { Cases }\end{array}$ & Relato de caso & Brasil & $\begin{array}{l}2 \text { casos de } \\
\text { infecção por } \\
\text { ZIKV na 36 } \\
\text { semana de } \\
\text { gestação. }\end{array}$ & ZIKV & $\begin{array}{l}\text { PCR quantitativo com amostra } \\
\text { de urina }\end{array}$ & $\begin{array}{l}\text { Cisto subependimário e } \\
\text { vasculopatia lenticuloestriada }\end{array}$ \\
\hline $\begin{array}{l}\text { Soares CN, et al., } \\
2016\end{array}$ & $\begin{array}{l}\text { Fatal encephalitis associated } \\
\text { with Zika virus infection in an } \\
\text { adult }\end{array}$ & Relato de caso & Brasil & Mulher, 47 anos & ZIKV & RT-PCR com amostra da urina & Encefalite fatal \\
\hline $\begin{array}{l}\text { Vieira MACS, et } \\
\text { al., } 2018\end{array}$ & $\begin{array}{l}\text { Encephalitis associated with } \\
\text { Zika virus infection and } \\
\text { reactivation of the varicella- } \\
\text { zoster virus in a Brazilian child }\end{array}$ & Relato de caso & Brasil & $\begin{array}{l}\text { Escolar, } 8 \text { anos, } \\
\text { masculino }\end{array}$ & $\begin{array}{c}\text { ZIKV e } \\
\text { reativação de } \\
\text { Varicella-zoster } \\
\text { virus } \\
\end{array}$ & PCR & Encefalite \\
\hline $\begin{array}{l}\text { Pereira LP, et al., } \\
2017\end{array}$ & $\begin{array}{l}\text { Encephalitis associated with } \\
\text { the chikungunya epidemic } \\
\text { outbreak in Brazil: report of } 2 \\
\text { cases with } \\
\text { neuroimaging findings }\end{array}$ & Relato de caso & $\begin{array}{c}\text { Fortaleza, } \\
\text { Nordeste, } \\
\text { Brasil } \\
\text { Morada Nova, } \\
\text { Nordeste, } \\
\text { Brasil } \\
\end{array}$ & $\begin{array}{l}\text { Homem, } 55 \text { anos. } \\
\text { Homem, } 74 \text { anos. }\end{array}$ & CHIKV & ELISA & Encefalite \\
\hline $\begin{array}{l}\text { Lucena-Silva N, } \\
\text { et al., } 2017\end{array}$ & $\begin{array}{l}\text { Encephalitis associated with } \\
\text { inappropriate antidiuretic } \\
\text { hormone secretion due to } \\
\text { chikungunya infection } \\
\text { in Recife, State of } \\
\text { Pernambuco, Brazil }\end{array}$ & Relato de caso & $\begin{array}{c}\text { Recife, } \\
\text { Pernambuco, } \\
\text { Brasil }\end{array}$ & Mulher, 48 anos & CHIKV & $\begin{array}{l}\text { RT-PCR com amostra do soro e } \\
\text { LCR }\end{array}$ & $\begin{array}{l}\text { Encefalite e Síndrome da } \\
\text { Hipersecreção Inapropriada de } \\
\text { Hormônio Antidiurético (SIADH) }\end{array}$ \\
\hline $\begin{array}{l}\text { Linden } V \text { van der, } \\
\text { et al., } 2017\end{array}$ & $\begin{array}{l}\text { Discordant clinical outcomes } \\
\text { of congenital } \\
\text { Zika virus infection in twin } \\
\text { pregnancies }\end{array}$ & Relato de caso & $\begin{array}{c}\text { Recife, } \\
\text { Pernambuco, } \\
\text { Brasil }\end{array}$ & $\begin{array}{l}2 \text { casos de } \\
\text { gestações } \\
\text { gemelares }\end{array}$ & ZIKV & ELISA & $\begin{array}{l}\text { Síndrome Congênita associada à } \\
\text { infecção pelo vírus Zika }\end{array}$ \\
\hline $\begin{array}{l}\text { Silva VP, et al., } \\
2020\end{array}$ & $\begin{array}{l}\text { Peripheral polyneuropathy } \\
\text { associated with Chikungunya } \\
\text { virus Infection }\end{array}$ & Relato de caso & $\begin{array}{l}\text { Região } \\
\text { Nordeste, } \\
\text { Brasil }\end{array}$ & Mulher, 66 anos & CHIKV & RT-PCR & Polineuropatia periférica \\
\hline $\begin{array}{l}\text { Mendonça AKRH } \\
\text { e Lima SO, } 2018\end{array}$ & $\begin{array}{l}\text { Comprometimento neurológico } \\
\text { de gêmeas monozigóticas } \\
\text { com infecção } \\
\text { congênita presumida pelo Zika } \\
\text { vírus: Relato de caso }\end{array}$ & Relato de caso & $\begin{array}{l}\text { Região } \\
\text { Nordeste, } \\
\text { Brasil }\end{array}$ & $\begin{array}{l}\text { Genitora, } 17 \\
\text { anos, com } \\
\text { gestação } \\
\text { gemelar } \\
\text { monocoriônica } \\
\text { diamniótica } \\
\end{array}$ & ZIKV & $\begin{array}{l}\text { Diagnóstico clínico- } \\
\text { epidemiológico }\end{array}$ & $\begin{array}{l}\text { Síndrome Congênita associada à } \\
\text { infecção pelo vírus Zika }\end{array}$ \\
\hline
\end{tabular}

Fonte: Benicio PJS, et al., 2020. 


\section{DISCUSSÃO}

Os resultados mostraram a circulação do DENV, CHIKV, ZIKV e WNV no Brasil. Nesse contexto, observou-se a semelhança dos sintomas que compõem o quadro clínico dos indivíduos infectados. Essas manifestações podem variar entre uma doença febril indiferenciada, moderada ou grave, erupções cutâneas, artralgia, síndromes neurológicas ou hemorrágicas. A variedade de agentes infecciosos envolvidos, as diversas formas de manifestação clínica, a inexistência de medidas imunoprofiláticas para a maioria das infecções e a dificuldade no diagnóstico preciso são indicadores de alta relevância das arboviroses no cenário da saúde pública do Brasil (LOPES N, et al., 2014).

Em relação à infecção pelo vírus da Dengue, a presente revisão identificou, ainda, relatos de complicações associadas. A doença caracteriza-se por um quadro febril agudo de espectro clínico variável, incluindo formas assintomáticas, oligossintomáticas ou graves, com a possibilidade de evoluir para óbito (RABELO ACL, et al., 2020). Inicialmente, manifesta-se com febre abrupta, geralmente alta, associada à cefaleia, mialgia, artralgia, dor retro-orbitária, adinamia, acompanhada ou não de exantema e prurido. Por volta de 2 a 6 dias de doença, podem estar presentes anorexia, náuseas, vômitos e diarreias. O vírus é transmitido principalmente pela picada de mosquito fêmea do gênero Aedes aegypti e ocorre na forma de quatro subtipos distintos: DENV-1, DENV-2, DENV-3 e DENV-4 (SILVA VP, et al., 2020).

Acerca das alterações neurológicas, os estudos de Mota MTO, et al. (2017) e Oliveira DB, et al. (2016) relataram casos de convulsão generalizada, confusão mental e mielite transversa aguda associadas à infecção por DENV. Em uma co-infecção DENV-CHIKV, Rosário MS, et al. (2018) descreveu um caso de encefalite e Síndrome de opsoclonia-mioclonia-ataxia. Esses resultados convergem com outros casos na literatura, que descrevem, ainda, a ocorrência de cefaleia, delírio, parestesia, síndrome de Guillain-Barré, meningoencefalite, hemorragia subaracnoide, acidente vascular cerebral hemorrágico, polineuropatia, neurite óptica, paralisia facial periférica e polirradiculoneurite aguda (FERREIRA MLB, et al., 2005). O comprometimento neurológico na infecção por DENV ocorre por formação de edema cerebral, hemorragia cerebral, hiponatremia, insuficiência hepática com encefalopatia porto-sistêmica, anóxia cerebral, hemorragia microcapilar e liberação de produtos tóxicos (FERREIRA MLB, et al., 2005).

Em virtude de ser um país com clima tropical, infecções por CHIKV revelaram-se um importante problema de saúde pública no Brasil. Os primeiros casos dessa infecção em lactentes evidenciados no país estão associados a manifestações de alto risco atípicas e graves causadas pelo vírus (DUARTE MCMB, et al., 2016). Tal arbovirose deve ser considerada no diagnóstico diferencial de manifestação cutânea bolhosa febril em crianças pequenas, principalmente em regiões de circulação do vírus (DUARTE MCMB, et al., 2016).

Os achados clínicos percebidos nos lactentes são bem específicos, como febre e manifestações cutâneas (em todos os casos), seguidos de irritabilidade, artralgia/artrite e vômitos; enquanto que os laboratoriais foram alta frequência de anemia, alteração do leucograma, aumento de celularidade no LCR (líquido cefalorraquidiano) e das aminotransferases. Além disso, os lactentes apresentaram exantema macular difuso, em sua maioria de início nos membros inferiores e tórax, e quatro casos lesões bolhosas, sem relato de úlceras (DUARTE MCMB, et al., 2016).

Por ser uma doença autolimitada, de baixa letalidade e de patogenia pouco esclarecida, não existe terapêutica específica para as infecções por CHIKV. A terapia conhecida é completamente suportiva, com ênfase na hidratação, analgesia, tratamento das lesões de pele e ao uso racional de antibióticos.

Os achados clínico-radiológicos também demonstraram a manifestação de encefalite em indivíduos que foram infectados por CHIKV em recente epidemia brasileira. Em análise do LCR desses pacientes, encontrou-se proteína elevada com pleocitose leve e predominância de linfócitos. Os mesmos achados contaram com encefalopatia leve em um dos casos e em outro, manifestações neurológicas mais graves sugestivas de encefalite e quadro agudo de fraqueza flácida com padrão axonal em eletromiografia e estudo da condução nervosa. Os achados de neuroimagem, semelhantes aos de pacientes descritos nos casos de 
encefalite associadas ao CHIKV, evidenciaram lesões bilaterais da substância branca frontoparietal com aumento do sinal em imagem ponderada por difusão na Ressonância Magnética, representado como um indício precoce de encefalite viral. Um dos casos também apresentou sinais de polirradiculite (PEREIRA LP, et al., 2017).

As manifestações menos comuns da infecção por CHIKV são de procedência cardiovascular, renal, ocular, neurológica e cutânea. No estado de Pernambuco, um indivíduo confirmado com infecção por CHIKV apresentou quadro de neuropatia e encefalite associadas a uma apresentação grave da síndrome da secreção inapropriada de hormônio antidiurético (SIADH). O quadro foi considerado atípico, pois não contou com alteração da temperatura do paciente. As queixas foram de intensa artralgia, bolhas nos pulsos e ocorrência de bolhas no palato. Outro sintoma considerado atípico e que precedeu a manifestação neurológica foi o desenvolvimento da SIADH com severa hiponatremia, exigindo ventilação mecânica. Os resultados dos exames laboratoriais revelaram aumento nos níveis de creatina fosfoquinase (CPK) e nos níveis de enzimas hepáticas, além de aumento discreto na celularidade do LCR. O sinal hiperintenso nos gânglios da base nas varreduras de ressonância magnética FLAIR T2 também representam um achado inespecífico (LUCENA-SILVA N, et al., 2017).

No que diz respeito à infecção por ZIKV, principalmente em imunodeprimidos, os impactos clínicos ainda são considerados imprevisíveis. Investigações no LCR e autópsia confirmaram alterações à nível de sistema nervoso central e meningoencefalite. Esta última, recentemente relatada por Carteaux G, et al. (2016). O exame microscópico do sistema nervoso central demonstrou inflamação perivascular, nódulos microgliais e neuronofagia, mais restrito ao córtex motor e ocasionando uma lesão pseudotumoral. Na Ressonância Magnética, grande parte da lesão foi identificada no giro frontal cingulado e superior com extensão em branco subcortical. Com exceção da subaracnoide, o parênquima cerebral restante apresentou leves mudanças - hipoteticamente causadas pela suspensão do regime imunossupressor, dentre elas: poucos linfócitos inflamatórios e ocasionais nódulos microgliais (SCHWARTZMANN PV, et al., 2017).

Outra descoberta clínica da infecção por ZIKV consiste em uma neuropatia sensório-motora leve, autolimitada, distal (BRIZZI KT, et al., 2014). Brizzi KT, et al. (2014) também descreveram formas da infecção, sendo as células de Schwann o alvo do agente infeccioso, que podem comprometer a função nervosa de forma aguda, resultando de inflamação do nervo segmentar com edema. Brizzi KT, et al. (2014) também mencionam que, dependendo da resposta imune, a desmielinização pode evoluir para uma resolução rápida ou progressiva. Os sintomas incluem fraqueza leve e limitada às extremidades, predominância de sintomas sensoriais e melhora rápida nos primeiros 7-10 dias com associação eletrofisiológica não reveladora. Uma vez que a descrição anterior envolve principalmente os nervos distais, estudos eletrofisiológicos normais não são inconsistentes com neuropatia aguda. A polineuropatia transitória aguda constitui uma síndrome benigna das complicações relacionadas ao ZIKV (NASCIMENTO OJM, et al., 2017).

Em outro caso de neuropatia sensorial, cumprindo todos os critérios propostos de Camdessanche et al. (2009), o paciente apresentou déficit sensorial assimétrico e severo, mas com força muscular preservada. $O$ estudo de condução nervosa revelou ampla anormalidade sensorial, mas as amplitudes do nervo sural não foram tão afetados quanto às amplitudes sensoriais dos nervos mediano e ulnar. Os resultados do estudo motor dos nervos e eletromiografia foram normais. A neuropatia sensorial, assim como a síndrome de MillerFisher, compartilha da ataxia como característica clínica central. Acredita-se que, ao invés de uma complicação direta da infecção por ZIKV, tenha ocorrido um quadro pós-infeccioso que desencadeou a neuropatia sensorial aguda / subaguda (MARTINEZ ARM, et al., 2017).

Durante uma epidemia brasileira de ZIKV em 2016, uma mulher de 47 anos apresentou sintomas infecciosos leves, como erupção cutânea e artralgia, que se desenvolveram rápido e agressivamente, levando à morte. Distúrbios do nível de consciência, sinais neurológicos focais, análise do LCR (que evidenciou pleocitose linfocítica e elevada concentração proteica) e achados sugestivos em TC determinaram o diagnóstico de encefalite. Manifestações neurológicas associadas à infecção tendem a ser subestimadas em virtude dos poucos sintomas apresentados (SOARES CN, et al., 2016). 
O status epiléptico, a presença de febre e a hiporresponsividade do paciente são imprescindíveis para a certeza no diagnóstico da encefalite, concordando assim com as definições da Brighton Collaboration. Uma das formas de apresentação da encefalite conta com um mecanismo de reativação, naqueles anteriormente infectados, do vírus da varicela-zoster que estava latente nos gânglios sensoriais devido infecção pelo ZIKV. $\mathrm{Na}$ encefalite por varicela-zoster, o indivíduo pode não apresentar erupção cutânea, febre, anormalidades de imagem e/ou pleocitose no LCR. Dessa forma, a detecção do DNA de varicela-zoster no LCR pode denotar comprometimento do SNC durante a infecção pelo ZIKV (VIEIRA MACS, et al., 2018).

De acordo com Brasil $P$, et al. (2016), da mesma maneira que ocorre na dengue e na chikungunya, $O$ quadro febril com erupções na pele também são características da infecção por Zika vírus. Além disso, destaca-se o potente neurotropismo do ZIKV, podendo resultar em uma apresentação atípica, conhecida como síndrome de Guillain-Barré (BRASIL P, et al., 2016). Como descrito por Wakerley BR (2014), a síndrome de Guillain-Barré engloba um significativo espectro de neuropatias auto-imunes, na qual aproximadamente dois terços dos pacientes relatam uma doença infecciosa aguda antecedendo o quadro neurológico. Os quadros descritos por Rosário MS, et al. (2016) evidenciaram uma doença de pródromo com erupção cutânea pruriginosa, febre, milagias ou artralgias, ocorrendo de 8 a 10 dias antes do início das manifestações neurológicas da síndrome de Guillain-Barré. Cao-Lormeau VM, et al. (2016) e Oehler E, et al. (2014) presumem que epidemias simultâneas de DENV e ZIKV, após infecção recente por ZIKV, podem ser um fator predisponente para desencadear a síndrome.

A síndrome congênita associada à infecção por ZIKV apresenta uma diversidade de alterações clínicas ou de neuroimagem sugestivas em crianças de mães infectadas durante a gestação, sobretudo no primeiro trimestre. Acredita-se que o vírus possa afetar as células progenitoras neuronais, resultando em retardo ou interrupção do desenvolvimento cerebral.

O quadro dessa síndrome envolve um espectro amplo de manifestações. Entre as alterações neurológicas, pode-se encontrar $\mathrm{o}$ atraso do desenvolvimento neuropsicomotor, hipoatividade motora, hipertonia, hiperreflexia, irritabilidade, hiperexcitabilidade, microcefalia, além de outras manifestações congênitas (FEITOSA IML, et al., 2016). Tais manifestações corroboram com os resultados descritos por Jucá E, et al. (2017), Noronha L, et al. (2016), Brito CAA, et al. (2018), Martines RB, et al. (2016), Regadas VC, et al. (2018), França TLB, et al. (2018) e Petribu NCL, et al. (2017). Esses estudos evidenciaram o comprometimento neurológico da síndrome, resultando em prejuízos para o desenvolvimento das crianças afetadas. Noronha L, et al. (2016) e Martines RB, et al. (2016) identificaram, ainda, associação da síndrome com aborto espontâneo e óbito fetal.

Em relação aos achados de neuroimagem, a síndrome congênita por ZIKV pode se apresentar com redução do diâmetro craniano, hidrocefalia, lissencefalia, hipoplasia cerebelar, ventriculomegalia ou calcificações cerebrais (MARTINES RB, et al., 2016; REGADAS VC, et al., 2018; JUCÁ E, et al., 2017; FRANÇA TLB, et al., 2018; PETRIBU NCL, et al., 2017). Outras infecções congênitas (toxoplasmose, rubéola, citomegalovírus, herpes simples, HIV e sífilis) também cursam com alterações do parênquima cerebral e podem apresentar calcificações, entretanto, as calcificações encefálicas na infecção por ZIKV ocorrem preferencialmente na transição córtico-subcortical, diferenciando-se das demais infecções congênitas. Além desses achados, o excesso de líquido ventricular e líquido extra-axial, alteração do corpo caloso e da substância branca podem estar presentes (FEITOSA IML, et al., 2016).

O vírus do Nilo Ocidental (WNV) é transmitido pela picada dos mosquitos dos gêneros Culex e Aedes, tendo sido introduzido no continente americano nos últimos 20 anos e, apenas em 2014, foi registrado o primeiro caso da infecção no Brasil (FIGUEIREDO LTM, 2019). Esse vírus está associado a infecção assintomática em mais de $80 \%$ dos casos (MARTINS MM, et al., 2020). Cerca de $20 \%$ pode apresentar um quadro autolimitado de doença febril aguda leve, cefaleia, fadiga, prostração, mialgia, sintomas gastrointestinais, rash maculopapular não pruriginoso (MARTINS MM, et al., 2020).

Em menos de $1 \%$ dos casos as manifestações neurológicas podem surgir e incluem meningite, encefalite, mielite e paralisia flácida (SILVA MTT, 2013). O estudo de Vieira MACS, et al. (2015) descreve o caso de um paciente que evoluiu com encefalite e paralisia flácida, corroborando com resultados 
semelhantes aos encontrados na literatura. Em relação ao mecanismo patológico, a encefalomioelite provocada pelo vírus caracteriza-se por proliferação viral em neurônios e células da glia, inflamação difusa perivascular, nódulos microgliais com perda de neurônios na substância cinzenta e branca do encéfalo, hipocampo, tálamo e medula espinhal (SILVA MTT, 2013).

Alguns fatores podem dificultar o diagnóstico, a exemplo das elevadas taxas de mutações do vírus, reação cruzada com outras arboviroses, baixas cargas virais e tempo de viremia (MARTINS MM, et al., 2020). A confirmação da infecção por WNV pode ser realizada pela identificação de anticorpos $\lg M$ e $\lg G$ específicos no sangue ou LCR usando os métodos ELISA e RT-PCR (MARTINS MM, et al., 2020, SILVA MTT, 2013).

\section{CONSIDERAÇÕES FINAIS}

O estudo permitiu identificar as principais alterações neurológicas associadas às infecções por ZIKV, DENV, CHIKV e WNV, tendo o Brasil como referência. Além do quadro clínico variável, essas arboviroses podem evoluir com complicações importantes no sistema nervoso, tais como meningite, encefalite, polineuropatia, neuropatia sensorial, mielite transversa aguda e a síndrome congênita associada à infecção por ZIKV. Notou-se que a dificuldade no diagnóstico das arboviroses consiste na semelhança da clínica apresentada pelos pacientes infectados. Além disso, a possibilidade de coinfecção também se mostrou um obstáculo para o diagnóstico acertado. Assim, considerando os aspectos locais que tornam o país endêmico para alguns arbovírus, destaca-se a necessidade de formulação de novas estratégias para o controle do vetor e educação da população.

\section{REFERÊNCIAS}

1. ANTUNES DE BRITO CA, et al. Zika in Pernambuco: rewriting the first outbreak. Revista da Sociedade Brasileira de Medicina Tropical, 2016; 49(5): 553-558.

2. AZEVEDO MB, de et al. Neurologic manifestations in emerging arboviral diseases in Rio de Janeiro City, Brazil, 2015-2016. Revista da Sociedade Brasileira de Medicina Tropical, 2018; 51(3): 347-351.

3. BRASIL P et al. Guillain-Barré syndrome associated with Zika virus infection. The Lancet, 2016; 387(10026): 1482.

4. BRASIL. Ministério da Saúde. Secretaria de Vigilância em Saúde. Boletim Epidemiológico. Brasília, 2020; 51(24).

5. BRITO CAA, et al. Persistent detection of Zika virus RNA from an infant with severe microcephaly-a case report. BMC infectious diseases, 2018; 18(1): 1-9.

6. DONALISIO MR, et al. Arboviroses emergentes no Brasil: desafios para a clínica e implicações para a saúde pública. Revista de Saúde Pública, 2017; 51(30).

7. DUARTE MCMB, et al. Infecção por Chikungunya em lactentes. Revista Brasileira de Saúde Materno Infantil, 2016; 16: 63-71.

8. FEITOSA IML, et al. Aspectos importantes da Síndrome da Zika Congênita para o pediatra e o neonatologista. Boletim Científico de Pediatria, 2016; 5(3).

9. FERREIRA MLB, et al. Manifestações neurológicas de dengue: estudo de 41 casos. Arquivos de Neuro-Psiquiatria, 2005; 63(2B): 488-493.

10. FIGUEIREDO LTM. West Nile virus infection in Brazil. Revista da Sociedade Brasileira de Medicina Tropical, 2019; 52.

11. FRAGOSO YD, et al. Guillain-Barré syndrome and dengue fever: report on ten new cases in Brazil. Arquivos de Neuro-Psiquiatria, 2016; 74(12): 1039-1040.

12. FRANÇA TLB, de et al. Growth and development of children with microcephaly associated with congenital Zika virus syndrome in Brazil. International journal of environmental research and public health, 2018; 15(9):1990.

13. JUCÁ E, et al. Hydrocephalus associated to congenital Zika syndrome: does shunting improve clinical features?. Child's Nervous System, 2017; 34(1): 101-106.

14. LINDEN V van der, et al. Discordant clinical outcomes of congenital Zika virus infection in twin pregnancies. Arquivos de Neuro-Psiquiatria, 2017; 75(6): 381-386.

15. LOPES N, et al. Características gerais e epidemiologia dos arbovírus emergentes no Brasil. Rev Pan-Amaz Saude, $2014 ; 5(3): 55-64$.

16. LUCENA-SILVA N, et al. Encephalitis associated with inappropriate antidiuretic hormone secretion due to chikungunya infection in Recife, State of Pernambuco, Brazil. Revista da Sociedade Brasileira de Medicina Tropical, 2017; 50(3): 417-422.

17. MARTINES RB, et al. Pathology of congenital Zika syndrome in Brazil: a case series. The Lancet, 2016; 388(10047): 898-904.

18. MARTINEZ ARM, et al. A novel phenotype Of Zika virus-related neurological disease: Sensory neuronopathy. Muscle \& Nerve, 2017; 57(2). 
19. MARTINS MM, et al. Arboviral diseases in pediatrics. J Pediatr, 2020; 96(S1): 2-11.

20. MENDONÇA AKRH, LIMA SO. Comprometimento neurológico de gêmeas monozigóticas com infecção congênita presumida pelo Zika vírus: Relato de caso. Rev. Bras. Saúde Mater. Infant., 2018; 18(1): 253-258.

21. MOTA MTO, et al. Transverse myelitis as an unusual complication of dengue fever. The American Journal of Tropical Medicine and Hygiene, 2017; 96(2): 380-381.

22. NASCIMENTO OJM, et al. Zika virus infection-associated acute transient polyneuritis. Neurology, 2017; 88(24): 2330-2332.

23. NORONHA L, de et al. Zika virus damages the human placental barrier and presents marked fetal neurotropism. Memórias do Instituto Oswaldo Cruz, 2016; 111(5): 287-293.

24. OLIVEIRA DB, de et al. Infection of the central nervous system with dengue virus 3 genotype I causing neurological manifestations in Brazil. Revista da Sociedade Brasileira de Medicina Tropical, 2016; 49(1): 125-129.

25. PEREIRA AGL, et al. Vigilância das síndromes neurológicas notificadas em um hospital federal em um contexto de epidemia de Zika, chikungunya e dengue. Rev Epidemiol. Controle Infecção, 2018.

26. PEREIRA LP, et al. Encephalitis associated with the chikungunya epidemic outbreak in Brazil: report of 2 cases with neuroimaging findings. Revista da Sociedade Brasileira de Medicina Tropical, 2017; 50(3): 413-416.

27. PETRIBU NCL, et al. Follow-up brain imaging of 37 children with congenital Zika syndrome: case series study. BMJ, $2017 ; 359$.

28. PUCCIONI-SOHLER M, et al. Neurological complications in dengue infection: a review for clinical practice. Arquivos de Neuro-psiquiatria, 2013; 71(9B): 667-671.

29. RABELO ACL, et al. Caracterização dos casos confirmados de dengue por meio da técnica de linkage de bancos de dados, para avaliar a circulação viral em Belo Horizonte, 2009-2014. Epidemiol. Serv. Saúde, 2020; 29(3).

30. REGADAS VC, et al. Microcephaly caused by congenital Zika virus infection and viral detection in maternal urine during pregnancy. Revista da Associação Médica Brasileira, 2018; 64(1): 11-14.

31. ROSÁRIO MS, et al. Guillain-Barre syndrome after zika virus infection in Brazil. The American journal of tropical medicine and hygiene, 2016; 95(5): 1157-1160.

32. ROSÁRIO MS; et al. Opsoclonus-myoclonus-ataxia syndrome associated with chikungunya and dengue virus coinfection. International Journal of Infectious Diseases, 2018; 75:11-14.

33. SCHWARTZMANN PV, et al. Zika virus meningoencephalitis in an immunocompromised patient. In: Mayo Clinic Proceedings. Elsevier, 2017.

34. SILVA ETC, et al. Análise espacial da distribuição dos casos de dengue e sua relação com fatores socioambientais no estado da Paraíba, Brasil, 2007-2016. Saúde debate, 2020; 44(125): 465-477.

35. SILVA VP, et al. Peripheral polyneuropathy associated with Chikungunya vírus Infection. Journal of NeuroVirology, 2020; 26: 122-126.

36. SILVA MTT. Viral encephalitis. Arq. Neuro-Psiquiatr., São Paulo, 2013; 71(9B): 703-709.

37. SOARES CN, et al. Fatal encephalitis associated with Zika virus infection in an adult. Journal of Clinical Virology, 2016; 83: 63-65.

38. SOUZA AS, et al. Fetal infection by Zika virus in the third trimester: report of 2 cases. Clinical Infectious Diseases, 2016; 63(12): 1622-1625.

39. VIEIRA MACS, et al. Encephalitis associated with Zika virus infection and reactivation of the varicella-zoster virus in a Brazilian child. Revista da Sociedade Brasileira de Medicina Tropical, 2018; 51(3): 390-392.

40. VIEIRA MACS, et al. West Nile virus encephalitis: the first human case recorded in Brazil. The American journal of tropical medicine and hygiene, 2015; 93(2): 377-379. 